\title{
Plight of UK research post-Brexit
}

\author{
As the negotiation deadline approaches, the impact of Brexit on research in the United Kingdom is already being felt.
}

T he United Kingdom has long been a powerhouse in research output and excellence, and clearly punches well above its weight. In a recent report by the Royal Society, it was estimated that the UK produces approximately $15 \%$ of the most highly cited research publications ${ }^{1}$. Interestingly, this research output has been successful partly due to the collaborative links with Europe and the rest of the world. It is estimated that $33 \%$ of publications from the UK are co-authored with researchers in the European Union and countries associated with the Horizon 2020 funding programme of research and innovation. In comparison, approximately $17 \%$ of publications are co-authored with the USA, indicating closer ties with Europe than America. This is further substantiated by the level of funding received from Europe in the past few years. Between 2007 and 2013, the UK was one of the largest recipients of funds from the EU for research, development and innovation, with an estimated $€ 6.9$ billion of the total $€ 55$ billion expenditure - second only to Germany ${ }^{2}$.

The EU has steadily increased its budget for research and innovation since its inception, with the current cycle having a budget of $€ 75$ billion $^{3}$. The next round of funding - the ninth framework programme, otherwise known as Horizon Europe to signify commitment and unity of the bloc - will be the world's largest single expenditure on research and innovation, and one that the UK has chosen to walk away from. The budget is estimated to be approximately $€ 100$ billion and will last for the next seven-year cycle (2021-2027) ${ }^{4}$. The involvement of the UK in Horizon Europe is still being negotiated and it is likely that the government will have to pay to participate as a 'third country participant', similar to Switzerland, which pays in on the basis of its economy. However, the UK would automatically lose its voting rights after Brexit and its role in decision-making would not be commensurate to its financial contribution.

The UK government has committed to matching funds for successful grant applications in the current cycle (Horizon 2020) from its Brexit bullion, or Brexitreadiness money. UK Research and

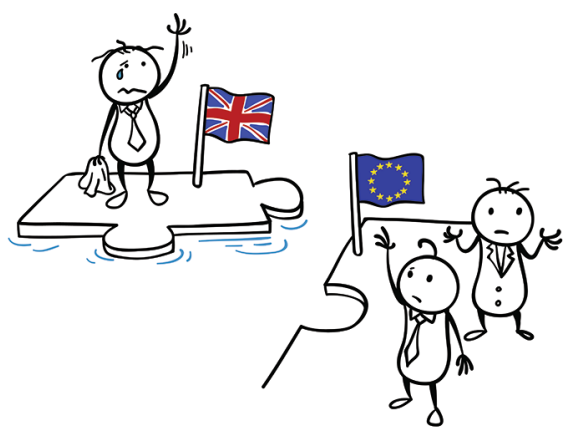

Credit: Ming Lok Fung/Getty

Innovation, which unifies all the research councils, will step in to manage applications in the event of a no-deal scenario ${ }^{5}$. However, there is currently no clear indication from UK Research and Innovation on whether or not funding will be available beyond 2020 . The government therefore has to guarantee that the shortfall in funding after Brexit will be matched through the research councils and higher education authorities. Currently, the UK spends approximately $1.7 \%$ of gross domestic product (GDP) on research and development, ranked 11th in Europe and below most major economies worldwide. The government has pledged to increase research and development spending to $2.4 \%$ of GDP by 2027 and a longer-term target of $3 \%{ }^{6}$. However, to reach this target, expenditure has to be amplified promptly, especially since a significant proportion of this expenditure originates from the business sector and non-profit organizations. This is further accentuated by the recent cuts in investment from the business sector, particularly in the automotive industry, due to Brexit.

Equally important is the need for legal clarity on the immigration status of the highly skilled workforce from Europe that currently carries out research in the UK. The attractiveness of the UK for employment in research has already been dented and will only diminish further in a no-deal scenario. Indeed, in a recent analysis by the Russell Group, which represents the 24 leading universities in the UK, it was found that there was an $11 \%$ rise in EU academics leaving their positions in the year following the referendum, compared to the previous year ${ }^{7}$. This so-called Brexit brain drain will undoubtedly hurt UK society particularly universities, which currently employ approximately $47 \% \mathrm{EU}$ and non-EU nationals in research laboratories.

The presidents of the four main UK national academies have publically urged the government to overhaul the current immigration system so that it is more competitive for researchers looking to work in the UK. In particular, they recommend scrapping the current $\mathfrak{1 3 0 , 0 0 0}$ salary threshold for a skilled worker visa; reducing the cost of visa applications, which are significantly higher than those of other leading nations; and completely ruling out a no-deal Brexit ${ }^{8}$. An issue that has been under-reported in the news is the status of the 1.3 million UK nationals living in mainland Europe, especially since EU freedom of movement would end immediately after a no-deal Brexit. The European Commission has recommended that all EU nations should adopt a "pragmatic approach" regarding the rights of UK nationals in the event of a no-deal scenario, with the UK expected to reciprocate this approach. However, there is still uncertainty regarding their legal status since this will vary from country to country.

It is clear that Boris Johnson is determined to lead the UK out of Europe on 31 October "come what may", but he underestimates the true cost of this departure on science. His government needs to put research and funding at the heart of their negotiations if the UK is to continue to produce cutting-edge scientific discoveries, while remaining an attractive location for researchers and their families to work.

Published online: 19 September 2019 https://doi.org/10.1038/s41563-019-0496-z

\footnotetext{
References

1. "No-deal" is a Bad Deal for Science (Royal Society, 2019).

2. Royal Society https://go.nature.com/2lv8UKj (2019).

3. Nat. Mater. 15, 589 (2016).

4. Nat. Mater. 17, 653 (2018)

5. UK Research and Innovation https://go.nature.com/2lUkDT0 (2019).

6. Industrial Strategy: Building a Britain Fit for the Future (HM Government, 2017)

7. Russell Group https://go.nature.com/2lVpWS9 (2019).

8. Royal Society https://go.nature.com/2lv9uYv (2019).
} 